San Jose State University

SJSU ScholarWorks

Master's Theses

Master's Theses and Graduate Research

Spring 1984

\title{
The Effect of Initial Muscle Glycogen Levels on Serum Urea Nitrogen Levels During Submaximal Exercise
}

Gayle Marie Yost

San Jose State University

Follow this and additional works at: https://scholarworks.sjsu.edu/etd_theses

\section{Recommended Citation}

Yost, Gayle Marie, "The Effect of Initial Muscle Glycogen Levels on Serum Urea Nitrogen Levels During Submaximal Exercise" (1984). Master's Theses. 4568.

DOI: https://doi.org/10.31979/etd.mg87-pvnm

https://scholarworks.sjsu.edu/etd_theses/4568

This Thesis is brought to you for free and open access by the Master's Theses and Graduate Research at SJSU ScholarWorks. It has been accepted for inclusion in Master's Theses by an authorized administrator of SJSU ScholarWorks. For more information, please contact scholarworks@sjsu.edu. 
The Effect of Initial Muscle Glycogen Levels on Serum Urea Nitrogen Levels During Submaximal Exercise

\author{
A Thesis \\ Presented to \\ the Faculty of the Department of \\ Human Ferformance \\ San Jose State University \\ In Fartial Fulfillment \\ of the Fiequirments for the Degree \\ Master of Arts
}

By

Gayle Marie Yost

May 1984 
APPROVED FOR

DEPARTMENT OF HUMAN PERFORMANCE

$\therefore$ zet

Dr. Carol Christensen

Elich Lidquint

Dr. Edith Lindauist

Eqwand Pree

Edward Price

Gamed R. Smart APPROVED FOR UNIVERSITY GRADUATE COMMITTEE 
Abstract

Initial muscle glycogen stores were altered to determine if subjects who exercised in a carbohydrate depleted state would use protein as an energy source. Six female subjects (23-30 yr) $r$ an on a treadmill for $1 \mathrm{hr}$ at $60 \% \mathrm{VO}_{2}$ max after carbohydrate loading (CHOL) and carbohydrate depletion $(\mathrm{CHOD})$. Serum urea nitrogen (N) and glucose were measured before exercise (ex), at $15 \mathrm{~min}$ ex, $60 \mathrm{~min}$ ex, $15 \mathrm{~min}$ recovery, and at $60 \mathrm{~min}$ recovery. Frior to the test period, each subject $r a n$ at $70-75 \% V_{2}$ max for 1 hour and then maintained a CHOL or $\mathrm{CHOD}_{\mathrm{D}}$ diet for 3 days or 1 day, respectively to insure appropriate initial muscle glycogen levels. Subiects then switched diets and repeated exercise periods. t-tests indicated there were no significant differences between preexercise and exercise serum urea N. An increaae in serum urea $N$ appeared at 15 min of recoverv following $\mathrm{CHOD}_{\mathrm{D}}(\mathrm{p} \times .01)$. At $15 \mathrm{~min}$ of ex there was an increase in glucose following CHOL. An increase in glucose occured at $60 \mathrm{~min}$ of recovery following CHOD. Significant differences were found between the serum urea $\mathrm{N}$ following the $\mathrm{CHO}$ and $\mathrm{CHO}_{\mathrm{D}}$ diets at all sampling times. A Fearson Froduct Moment correlation coefficient showed weak to moderate relationships between glucose and serum urea $N$. It was concluded that serum urea $N$ levels can be altered by diet. and that under certain conditions, such as low muscle glycogen, there appears to be an increase in the contribution of protein as an energy source. Also in addition to their role as fuel, amino acids may be involved in maintaining blood glucose levels during long-term exercise. 


\section{ACKNOWLEDGEMENTS}

I would like to thank the following people for their help and support in completing this study: Fichard Sehroeder for his time and expertise, and for the use of the facilities at De Anza College; Carol Christensen, the chairperson of my committee for the suggestions she made for the project: Edith Lindquist. for her suggestions and assistance with the statistical analyses; Edward Price for his help in starting this project; and finally a special thanks to my friends who were willing to be my subjects, and donate their time and energy.

This study was partially funded by a grant from Falmer College Chiropratic West. 
TABLE OF CONTENTS

Page

ABSTRACT ....................... . . i i

ACKNOWLEDGEMENTS . . . . . . . . . . . . . . . i i

TABLE OF CONTENTS . . . . . . . . . . . . . . iv

LIST OF TAELES . . . . . . . . . . . . . . . . . vi vi

Chanter

1. INTFODUCTOFIY MATERIAL . . . . . . . . 1

Introduction ............. 1

Statement of the Froblem . . . . . . . 2

Research Hyoothesis . . . . . . . . 2

Definitions ........... . 2

Delimitations . . . . . . . . . 4

Limitations . . . . . . . . . . 4

Significance.............. 4

2. REVIEW OF LITERATURE . . . . . . . . . . 5

Frotein Metabolism in Skeletal Muscle . . 5

Glucose Alanine Cycle . . . . . . . . 7

Frotein Metabolism During Exercise . . 10

Effects of Diet and Exercise on Muscle

Glycogen Levels . . . . . . . . . 14

Summary . . . . . . . . . . . 18

3. PROCEDURES . . . . . . . . . . . . 19

Sub jects... . . . . . . . . . 19

Test Schedule. . . . . . . . . . 19 
Exercise Sessions .. . . . . . . 22

Maximum Oxygen Consumption . . . . . 22

Submaximal Exercise . . . . . . . 22

Treatments . . . . . . . . . . 24

Measurements . . . . . . . . . . 24

Design... . . . . . . . . . . 26

Statistical Analysis... . . . . . 26

4. RESULTS AND DISCUSSION . . . . . . . 27

Results . . . . . . . . . . 27

Discussion.......... . 34

5. SUMMARY. CONCLUSIONS, AND FECOMMENDATIONS . 41

Summary . . . . . . . . . . . 41

Conclusions .. . . . . . . . 42

fiecommendations . . . . . . . 43

REFEFENCES ............... 44

APPENDICES.................. 48

A. Informed Consent Form . . . . . . . . . 48

B. Carbohydrate Loaded Diet List . . . . . . 50

C. Carbohydrate Depleted Diet List . . . . . . 53

D. Serum Glucose Concentrations Before, During,

and After 1 Hour of Exercise at $60 \%$ VQz max. 55

E. Serum Urea Nitrogen Concentrations Before,

During, and After 1 Hour of Exercise at

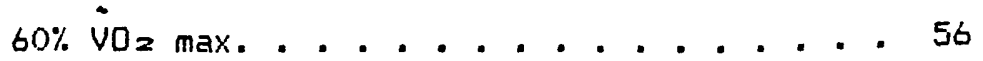




\section{LIST OF TABLES}

Page

Table

1. Fhysiological Characteristics of Subjects . . 20

2. Experimental Test Schedule......... 21

3. Bruce Frotocol for Maximum Oxygen Consumption. . 23

4. Effects of Carbohydrate Loaded and Carbohydrate

Depleted Diets on Serum Glucose for Five

Subiects Eefore, During, and After 1 Hour of

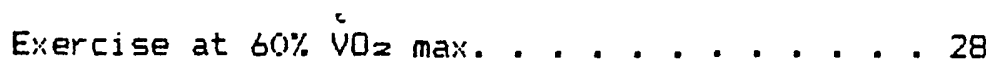

5. Effects of Carbohydrate Loaded and Carbohydrate

Depleted Diets on Serum Urea Nitrogen for Five

Subjects Eefore, During, and After 1 Hour of

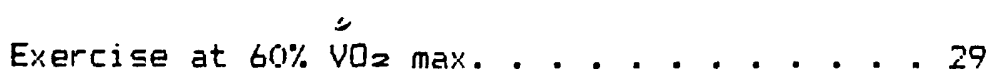

6. Statistical Analyses for Serum Glucose

Concentrations Before, During, and After

1 Hour of Exercise at $60 \% \dot{v}_{2} \max$. for Five

Subiects . . . . . . . . . . . . 30

7. Statistical Analyses for Serum Urea Nitrogen

Before, During, and After 1 Hour of Exercise

at $60 \% \dot{\mathrm{v}} \mathrm{O}_{2} \max$. for Five Subjects . . . . . 32

8. Relationship between Serum Glucose and Serum

Urea Nitrogen Following a Carbohydrate

Loaded and a Carbohydrate Depleted Diet . . . 33 
CHAPTER I

Introductory Material

\section{Introduction}

Until recently the literature regarding energy substrate utilization during exercise failed to recognize the contribution of protein metabolism as an energy source. Astrand and Fodahl (1977) maintain that the oxidation of amino acids plays an insignificant role for muscular contraction when energy supplies are sufficient. In contrast, a number of studies have demonstrated a significant increase in urinary and sweat nitrogen excretion in exercising men who were in a hypercaloric state (Consolazio, Johnson, Nelson, Dramise \& Skala, 1975; Gontzoa, Sutzesca, \& Dumitrache, 1974; and Mole \& Johnson, 1971).

The relationship between preexercise muscle glycogen levels and protein catabolism was investigated by Lemon and Mullins (1980). They found significant differences in urea nitrogen excretion between carbohydrate loaded and depleted subjects, with the carbohydrate depleted subjects demonstrating sweat urea nitrogen levels twice as high as carbohydrate loaded subjects. Their results suggest that protein serves as an energy substrate in carbohydrate depleted subjects and that long term exercise is similar to starvation which also uses protein as an energy substrate (Lemon \& Mullins, 1980 ). The increase in the protein catabolism can be explained by the branched chain amino acid-alanine cycle which suggests that the 
source of catabolic protein is from amino acid transamination within skeletal muscle to form alanine from glucose derived pyruvate, which is then deaminated to pyruvate in the liver (Felig \& Wahren, 1971; Lemon \& Mullins, 1980; and Odessey, Khairallah, \& Goldberg, 1974). The cycle allows the conversion of pyruvate to alanine to provide energy without consumption of glucose. Therefore, it seems that amino acids,, specifically the branched chain amino acids, could play an important role in providing tricarboxylic acid cycle intermediates and maintaining blood glucose levels in prolonged exercise.

\section{Statement of the Problem}

This investigation examined serum urea nitrogen levels in carbohydrate loaded and carbohydrate depleted subjects during one hour of submaximal exercise and one hour of recovery to determine the relationship between initial muscle glycogen and serum urea nitrogen levels. The relationship between serum urea nitrogen and serum glucose levels was also examined.

\section{Research Hypothesis}

In this study the following hypotheses were tested: (a) during exercise, carbohydrate depleted subjects would significantly increase their serum urea nitrogen levels from preexercise levels, and (b) there would be a significant reciprocal relationship between serum glucose and serum urea nitrogen levels.

\section{Definitions}

Amino Acid Catabolism is the process where the amino groups of the individual amino acids are removed and then incorporated into the compound urea, which is excreted in urine. The remainder of the 
amino acid called carbon skeletons are converted into molecules that are used to produce glucose by gluconeogenesis or they are oxidized by the tricarbonylic acid cycle to produce carbon dioxide.

The Branched Chain Amino Acid are leucine, isoleucine, and valine.

The Eranched Chain Amino Acid Alanine Cycle is a modification of the original glucose alanine cycle which suggests transamination of branched chain amino acids with alpha ketoglutarate form glutamate. Glutamate may then donate its amino group to pyruvate to form alanine, which then continues to follow the pathway of the glucose alanine cycle.

Carbohydrate Loaded is a condition where the initial muscle glycogen level is approximately double the resting glycogen level.

Carbohydrate Depleted is a condition where the initial muscle glycogen level is approximately one half of normal resting glycogen levels.

Deamination is the enzmatic removal of an amine group (-NHz) from an amino acid to form ammonia and an alpha keto acid.

Gluconeogenesis is the formation of carbohydrates from noncarbohydrates. This occurs primarily in the liver and kidney.

Glucose Alanine Cycle is a cycle in which glucose extracted from or released from tissue glycogen stores is converted by muscle to pyruvate. Transamination of pyruvate results in formation of alanine which is released into the circulation. Glucose derived alanine is then taken up by the liver where it is reconverted to glucose and released into the circulation, where it can again be taken up by the 
muscle.

Iransamination is the transfer of an amine $\left(-\mathrm{NH}_{2}\right)$ group from one compound to another without the formation of ammonia.

\section{Delimitations}

This study was delimited to six female volunteer subjects between the ages of 23 and 30 years. Limitations

1. The monitoring of the diet protocol for each diet regimen was the responsibility of the subjects and not monitored in the laboratory.

2. The individual differences in the initial level of training might have affected the results.

\section{Significance}

The review of literature indicated that the effects of exercise on protein catabolism had not been investigated with women subjects. Therefore, this investigation of carbohydrate loaded and depleted women provides new data on protein catabolism by women during exercise. 
CHAPTEF II

Review of Literature

This examination of related literature is divided into sections to show the principles of amino acid metabolism and how the application of these principles may have important effects on blood glucose levels during pralonged exercise. The sections are as follows: 1) amino acid metabolism in skeletal muscle, 2) the glucose alanine cycle, 3) amino acid metabolism during exercise, and 4) the effects of diet and exercise on muscle glycogen levels. Protein Metabolism in Skeletal Muscle

In the past, the liver has been considered the major site for degradation and synthesis of amino acids. Amino acids in the muscle were thought to be precursors for protein synthesis or waste products of protein catabolism to be transported to the liver. Later studies have provided evidence that many amino acids can be oxidized within skeletal muscle. Goldberg and Ddessey (1972) demonstrated that rat skeletal muscle and diaphragms incubated with $14 \mathrm{C}$ labeled leucine, isoleucine or valine, are able to catabolize alanine, glutamate and asparatate as well as the three branched chain amino acids. The muscle did not significantly oxidize other amino acids such as glysine, serine, proline, threonine, methionine, lysine, tyrosine, phenylalanine, histidine, and tryptophan (Goldberg \& Odessey, 1972). Since the branched chain amino acids had a faster rate of oxidation in muscle than in the liver (Goldberg \& Odessey, 1972), and since 40 
percent of our body mass is made up of skeletal muscle, it was concluded that amino acid catabolism by skeletal muscle could supply the major source of energy from amino acids.

A number of studies have dealt with varying intervals of food deprivation and amino acid metabolism. Felig, Owen, Wahren and Cahill (1969) studied 20 amino acids in obese subjects undergoing a total 6 week: starvation period. They also studied a group of subjects in a postabsorptive state, which is a 12 to 14 hour fast, and a brief fast of 36 to 48 hours. During the first 5 days of starvation there was an increase in plasma branched chain amino acids. After 6 weeks of starvation, the plasma concentration of 13 amino acids decreased with alanine decreasing the most. The alanine decreased rapidly during the first 5 to 10 days of starvation. After 6 weeks of starvation the significant decrease in splanchnic alanine uptake was due to the decreased arterial concentration. After the fast for 36 to 48 hours, the amino acid exchange was similar to the postabsorptive state, but there was a significant increase in the arterio-hepatic venous difference for alanine which was due to an increase in splanchic uptake of plasma alanine. Felig et al., (1969) suggested the decrease in plasma alanine concentration was caused by increased and preferred splanchnic use of alanine during early starvation resulting in alanine depletion. Low plasma alanine caused a decrease in splanchnic uptake which decreased gluconeogenesis and protein utilization during long-term starvation.

In a study by Felig, Pozefsky, Marliss and Cahill (1970), subjects who were in a postabsorptive state for 12 hours showed a 
significant release of 16 amino acids from the forearm muscle in a resting state. The alanine release exceeded all other amino acids. After a 6 week starvation period, subjects showed a significant decrease in amino acid release with the greatest decrease in alanine. In another study, out of 20 amino acids studied, alanine was responsible for 48 percent of the total splanchnic uptake for subjects in the postabsorptive state (Felig \& Wahren, 1971).

Goldberg and Odessey (1972) demonstrated that the diaphragms of rats fasted 67 hours had oxidation rates 2.7 to 4.5 times faster than fed rats for the branched chain amino acids. Also the production of carbon dioxide from al anine was increased by 43 percent in the diaphragms of animals fasted for 3 days, while the other amino acids did not increase their oxidation rates in muscles of fasted rats. Ruderman and Berger (1974) reported that fasting rats for 48 hours caused a 55 percent increase in the release of alanine, while there was no increase in the release of other amino acids.

The results of these studies indicate that alanine is released from the muscle at a greater rate than all other amino acids after fasting 12 to 48 hours. Also, in the resting state alanine is the main amino acid extracted by splanchnic circulation, accounting for 48 percent of the amino acid uptake by the liver (Felig et al., 1969; Felig \& Wahren, 1971; and Ruderman \& Berger, 1974). Therefore, it seems that food supply to the organism can influence the formation and release of alanine from skeletal muscle and possibly control the rate of gluconeogenesis.

Glucase Alanine Cycle 
Alanine may also be important in transporting ammonia from the skeletal muscle to the liver. Anmonia is a by product of the breakdown of branched chain amino acids (Lowenstein, 1972). This released ammonia is toxic to skeletal muscle because the muscle lacks the enzymes to form urea from ammonia (Goldberg \& Chang, 1978).

Felig et al., (1970) and Mallette, Exton and Park, (1969) suggested the existence of a glucose alanine cycle. They believed the significant extraction of alanine by the liver supports their theory that alanine is important in amino acid metabolism. The cycle begins with glucose uptake into the muscle which then goes through glycolysis to produce pyruvate. The pyruvate accepts an amino group to form alanine, which then enters the blood and is carried to the liver where the amino nitrogen is metabolized to urea for excretion and the carbon skeletons are used for gluconeogenesis. The glucose synthesized by the liver can then be returned to the peripheral tissue (Felig et al., 1970; Mallette et al., 1969). The glucose alanine cycle as originally proposed allowed the catabolism of amino acids in the muscle without accumulation of ammonia in the muscle.

Later studies also showed the importance of alanine in amino acid metabolism and the relationship of the branched chain amino acids to alanine synthesis. These studies indicated that alanine production is related to the catabolism of branched chain amino acids (Chang \& Goldberg, 1978; Goldberg et al., 1978 and Odessey et al., 1974). During fasting, rat diaphragms increased alanine production at the same time the rate of degradation for the branched chain amino acids increased. Leucine, isoleucine, and valine all increased the 
intracellular concentration of glutamate and increased the production of alanine and glutamine (Chang \& Goldberg, 1978; Odessey et al., 1974). Fram these studies the branched chain amino acid al anine cycle was proposed. Chang and Goldberg (1978) suggested that al anine and glutamine were synthesized within the skeletal muscle by transamination of the branched chain amino acids with alpha ketoglutarate to form glutamate. Glutamate may then transaminate its amino group to pyruvate which may form alanine or it can use free ammonia to form glutamine.

Chang and Goldberg (1978) reported that the production of alanine and glutamine is also limited by the availability of carbon chains. The following amino acids were determined to be the only possible amino acid sources of carbons for alanine and glutamine production: asparate, asparagine, glutamine, isoleucine, and valine. Chang and Goldberg's study (1978) also determined that 97 percent of the carbons of alanine, pyruvate, and lactate were from blood glucose and not from amino groups released from protein catabolism.

Other investigators disagreed with the theory that alanine is formed from blood glucose. Garber, Karl and Kipnis (1976) and Goldstein and Newsholme (1976) believe that alanine is formed from other amino acids derived from the net breakdown of muscle protein. According to their model, during fasting the degradation of certain amino acids will produce pyruvate which can then be transaminated to alanine. They reported that asparate, cysteine, leucine, valine, methionine, isoleucine, serine, threonine, and glycine significantly increased alanine synthesis and the release of alanine from the 
muscle. Their findings contradict Goldberg and Ddessey (1972) who reported that only asparate, asparagine, glutamate, isoleucine, and valine can provide carbons for glutamine and alanine synthesis. The other amino acids reported by Garber et al., (1976) to increase alanine synthesis, failed to produce carbon dioxide in rat diaphragms or other rat muscles which indicated that they cannot be converted into tricarboxylic acid cycle intermediates or pyruvate Goldberg \& Ddessey, 1972); Chang \& Goldberg, 1978). Therefore, these other amino acids cannot provide the carbon skeletons for alanine or glutamine synthesis.

To determine the source of pyruvate for alanine synthesis, the rate of pyruvate production from blood glucose and the rate of pyruvate synthesis from amino acids derived from net protein catabolism of muscle were investigated. The results showed only 3 percent of pyruvate for alanine synthesis was supplied by amino acids produced from a net protein breakdown (Chang \& Goldberg, 1978). Blood glucose appears to be the main source of carbon for alanine production as originally proposed in the glucose alanine cycle (Chang \& Goldberg, 1978; Felig et al., 1970; Mallette et al., 1969). Protein Metabol ism During Exercise

In early experiments dealing with exercise, it was found that muscular work is accompanied by ammonia production (Schwartz, Lawrence, \& Roberts, 1958). Brodan, Kuhn, Pechar, and Tomkova (1976) reported serum ammonia increased significantly during exercise and the ammonia production was directly proportional to the muscular work. 
Rougier and Babin (1975) studied the effects of exercise intensity on nitrogen catabolism. The blood urea concentration increased 25 percent for men exercising on a treadmill with a 5 percent grade for $15 \mathrm{minutes}$ at $14 \mathrm{~km}$ an hour. After 1 hour of recovery the urea concentration increased 48 percent. They also reported a 40 percent increase for subjects who ran until exhaustion at varying speeds. After 1 hour of recovery the blood urea concentration rose to $\mathbf{5 4}$ percent and during the next day it remained 21 percent higher than normal. They concluded from their results that exercise will cause an increase in protein catabolism if it is sufficient in intensity and duration.

Felig and Wahren (1971) examined the arterial concentration and net exchange across the leg and splanchnic vascular beds for 19 amino acids in male subjects exercising on a bicycle ergometer at different intensities. During mild exercise $(400 \mathrm{kgm} / \mathrm{min})$ alanine concentration rose 20 to 25 percent and with more intense exercise $(800 \mathrm{~kg}$ to $1200 \mathrm{kgm} / \mathrm{min})$ alanine rose 60 to 96 percent. The concentration of the other amino acids remained the same during mild exercise and rose 8 to 35 percent for isoleucine, leucine, methionine, tyrosine, and phenylalanine after 40 minutes of moderate and severe work. The alanine uptake by the liver exceeded all other amino acids at all work intensities. During exercise there was a direct correlation between arterial alanine and arterial pyruvate (Felig \& Wahren, 1971). There was no significant correlation for any other amino acid and pyruvate. This provides further evidence for the relationship between alanine and glucose metabolism. 
Ahlborg, Felig, Hagenfeldt, Hendler, and Wahren (1974) studied arterial concentrations and substrate exchange across the leg and splanchnic beds for glucose, free fatty acids, lactate, amino acids, and pyruvate during long-term exercise. The subjects were fed a diet consisting of 55 percent carbohydrates, 30 percent fat, and 15 percent protein the week prior to the exercise program. After a 12 hour fast, subjects exercised on a bicycle ergometer for 4 hours at 30 percent of maximum oxygen uptake. The purpose of the study was to examine the role of glycogen and gluconeogenesis in the maintenance of glucose hemeostasis during long-term exercise. The glucose concentration remained constant during the first 40 minutes of exercise and then gradually decreased to 30 percent below resting levels. The uptake of glucose by the leg was 10 times the resting levels after 40 minutes of exercise and 12 times as much at 4 hours of exercise. During the first 40 minutes, splanchnic glucose production increased 100 percent above resting levels and remained at the same level. The glucose production exceeded glucose uptake by the legs during the first 40 minutes, but then it was unable to keep up with glucose utilization. The splanchnic glucose output used approximately 75 percent of liver glycogen stores. After 4 hours of exercise, the splanchnic uptake of lactate, pyruvate, glycerol, and alanine increased. The increase in splanchnic uptake of these gluconeogenic precursors after 4 hours of exercise provided 45 percent of the glucose released. At rest and at 40 minutes of exercise, the splanchnic uptake of these gluconeogenic precursors provided only 20 to 25 percent of the glucose released. 
In this same study (Ahlborg et al., 1974), examination of the amino acids showed that only alanine was significantly released from the leg during exercise. At 40 minutes alanine output from the muscle increased slightly and at 4 hours it increased 3 times more than in the resting state. In contrast, the branched chain amino acids in the resting state demonstrated increased net uptakes. The splanchnic uptake of alanine increased 100 percent after 4 hours of exercise. Threonine, serine, proline, and glycine also increased during exercise. Again, the branched chain amino acids showed a different response, the splanchnic output significantly increased for the branched chain amino acids after 4 hours.

A number of conclusions can be drawn from these findings (Ahlborg et al., 1974). First, during 4 hours of exercise, the blood glucose level decreases because splanchnic glucose output is unable to match the increased glucose utilization by the exercising leg muscles. Second, during prolonged exercise, as glycogen stores become depleted, the contribution of gluconeogenesis to splanchnic glucose output increases.

Wahren, Felig, Hendler, and Ahlborg (1973) examined the relationship between amino acid metabolism and glucose during a 40 minute recovery period. Male subjects between the ages of 22 and 45 years were used in this study. Wahren et al., (1973) reported an 11 percent increase in the glucose concentration during the 40 minute exercise period and it continued to increase another 11 percent during the first 5 minutes of recovery. This was followed by a gradual return to a resting level concentration. Both pyruvate and 
lactate significantly increased during the first 10 minutes of exercise and then gradually decreased. The lactate and pyruvate concentrations did not return to preexercise concentrations after 40 minutes of recovery. Plasma al anine concentration rose 80 percent during exercise and during recovery it gradually decreased to its preexercise concentration. The relationship between alanine and glucose metabolism during recovery was demonstrated by the significant relationship noted between arterial alanine and arterial pyruvate concentration (Wahren et al., 1973). The splanchnic exchange of amino acids was examined and the net amino acid exchange remained unchanged during exercise. During recovery, al anine uptake increased 50 to 60 percent when compared to resting and exercise levels. The uptake for several other glucogenic amino acids increased at 20 and 40 minutes of recovery. The leg muscles increased their uptake of glucose and al anine release during recovery.

Wahren et al., (1973) findings indicate that normal splanchnic glucose output is quickly achieved after exercise and the uptake of precursors for gluconeogenesis increases during recovery. Also, the increased glucose uptake and alanine release by the leg during recovery indicated that the glucose alanine cycle is involved during the recovery period.

\section{Effects of Diet and Exercise on Muscle Glycogen Levels}

Gaesser and Brooks (1980) reported that in the absence of food, the cardiac muscle in rats run to exhaustion following a 12 hour fast, was able to restore to preexercise glycogen levels in 4 hours, 
while skeletal muscle reached only 51 percent of preexercise glycogen levels in 4 hours. The postexercise blood glucose concentration was 36 percent of the preexercise level and after 4 hours of recovery it had increased to 84 percent of preexercise levels. This increase parallelled the cardiac and skeletal muscle glycogen repletion during recovery. The source of the glycogen is unknown, but since glycogen stores in the liver were depleted, gluconeogenesis must have been providing the precursors for glycogen repletion in the cardiac and skeletal muscle. The authors suggested the source of the carbon skeleton for endogenous glucose synthesis was related to amino acid transamination and deamination within skeletal muscle.

MacDougall, Ward, Sale, and Sutton (1977) reported that male subjects who were glycogen depleted showed a complete return to preexercise glycogen levels with 24 hours and that ingestion of a high carbohydrate diet did not increase the rate of repletion. In their investigation, 6 men exercised to exhaustion on a bicycle ergometer at high intensities. The muscle glycogen level was 28 percent of preexercise levels at exhaustion. The muscle glycogen increased 39 percent during the first 2 hours when diet was restricted and continued to increase after food was ingested to 102 percent at 24 hours. The subjects were either fed diets containing 50 percent carbohydrates or they ate the same diet plus an additional 357 grams of pure carbohydrate. The authors concluded that the rate of glycogen repletion after high intensity, intermittent exercise was not influenced by a high carbohydrate diet and that preexercise levels will be reached within 24 hours. 
Hermansen, Hultman, and Saltin (1967) demonstrated that male subjects, worked to complete exhaustion on a bicycle ergometer at 76 percent $\mathrm{VO}_{2}$ max., showed significant decreases in their initial muscle glycogen levels. Subjects exercised for 20 minutes followed by a 15 minute rest. This schedule was repeated until exhaustion. The average exercise time was 85 minutes. Hermansen et al., (1967) found the glycogen in the resting muscle was 1.6 grams/100grams and after exercise it was .06 grams/100grams.

Bergstrom, Hermansen, Hultman, and Saltin (1967) reported that muscle glycogen concentration can be significantly increased by intensely exercising to deplete the glycagen stores and then ingesting a diet rich in carbohydrates. Only moderate increases in muscle glycogen levels occurred when the carbohydrates were taken without previous exercise. Bergstrom et al., (1967) demonstrated that it is possible to significantly vary muscle glycogen levels by providing subjects with different diets after intensive exercise to exhaustion. The diets provided were a mixed diet (M), a fat plus protein diet $(P)$, and a carbohydrate diet (C). The subjects first ate a mixed uncontrolled diet and then exercised on a bicycle ergometer at 75 percent $\dot{V}_{2}$ max. to exhaustion with a mean time of 125 minutes. Then half were fed the $P$ diet and half the $C$ diet for 3 days and then performed the same exercise again with an average time of 58 minutes after the $P$ diet and 189 minutes after the $C$ diet. The groups then switched diets and followed the appropriate exercise schedule. The results showed that after 3 days, subjects of the $P$ diet had returned to 50 percent of initial glycogen levels while the 
C diet increased their glycogen levels far beyond the initial level. The subjects who received the $\mathrm{F}$ diet before the $c$ diet reached higher glycogen levels. This indicated that the period with low muscle glycogen associated with the $P$ diet augmented the increased glycogen synthesis when the carbohydrates were ingested.

To determine if the rate of protein degradation is related to glycogen levels within the muscle, Lemon and Mullins (1980) examined urea nitrogen excretion in carbohydrate loaded and carbohydrate depleted male subjects. They reported that the urea nitrogen significantly increased in carbohydrate depleted subjects during exercise and recovery while the urea nitrogen for the carbohydrate loaded subjects was insignificant. Lemon and Mullins (1980) concluded that long-term exercise is similar to short term starvation because protein acts as an important energy source in carbohydrate depleted subjects. They suggested three possible explanations for increased protein catabolism during exercise. First, amino acids may be transaminated within the muscle to form alanine, which is then deaminated to pyruvate which can then enter the tricarboxylic acid cycle. The second possibility is that protein utilization for muscular contraction is related to the supply of substrates. The third possibility is that the ability to synthesize ATP decreases because of low muscle glycogen. This affects the integrity of the cell membrane because ATP is needed to synthesize phosopholipids. The results would be an efflux of enzymes which could be broken into their amino groups, deaminated, and the remaining carbons used in the tricarboxylic acid cycle. 
Summary

During starvation and exercise, protein catabolism is increased and the skeletal muscle has an increased capacity to oxidize branched chain amino acids. Studies of amino acids during starvation, the resting state, and exercise all reported the importance of alanine and the relationship of the branched chain amino acids with al anine formation. The breakdown of the branched chain amino acids produces ammonia. The glucose alanine cycle provides a pathway for the release of ammonia and it provides carbon skeletons for gluconeogenesis. The contribution of gluconeogenesis to splanchnic glucose output increases as glycogen stores become depleted. Therefore, it is possible that the relationship between amino acid metabolism and carbohydrate metabolism during exercise is more significant than originally believed and that amino acid catabolism plays an important role in long-term exercise. 


\section{CHAPTER III}

\section{Procedures}

This chapter is divided into the following sections: subjects, test schedule, exercise sessions, treatments, measurements, design, and statistical analysis.

\section{Subiects}

Six female volunteer subjects between the ages of 23 and 30 years participated in this study. They were apparently healthy and physically active women with varying levels of training. Table 1 contains the physiological characteristics of subjects. The subjects were familiarized with testing procedures and each subject signed a human subject release form which stated the participant's rights during this study. The release form, presented in appendix $A$, was approved by the San José University Human Subjects Committee prior to initiation of the study.

\section{Test Schedule}

Subjects were randomly divided into two groups. The test schedule for both groups is presented in Table 2 . The three subjects in Group $A$ were tested on a Quinton treadmill to determine maximum oxygen consumption (voz max.). On day 4, subjects exercised on a treadmill at 70 to 75 percent $\dot{V O}_{2}$ max. for 1 hour. Subjects then followed the carbohydrate loaded diet for 3 days. The subjects then exercised at 60 percent $\hat{V}_{z}$ max. for 1 hour. Five days later, subjects exercised at 70 to 75 percent $\mathrm{V}_{2}$ max. for 1 hour and were 
Table 1

Physiological Characteristics of Subjects

\begin{tabular}{|c|c|c|c|c|c|c|c|}
\hline Sub jects & $\begin{array}{l}\text { Age } \\
\text { (yrs) }\end{array}$ & $\begin{array}{l}\text { Wt. } \\
(\mathrm{kg})\end{array}$ & $\begin{array}{r}\operatorname{Max} \cdot \mathrm{HR}^{\circ} \\
(\mathrm{bpm})\end{array}$ & $\begin{array}{l}\text { VEe } \\
\text { (L/min) }\end{array}$ & $\begin{array}{l}\mathrm{VO}_{2} \mathrm{a} \\
(\mathrm{L} / \mathrm{m})\end{array}$ & $\begin{array}{l}\dot{v}_{0=m 1}= \\
(m 1 / k g / m)\end{array}$ & $\mathrm{R}^{*}$ \\
\hline 1 & 30 & 54.1 & 188 & 102.0 & 2.57 & 48 & 1.30 \\
\hline 2 & 23 & 57.0 & 188 & 53.0 & 2.64 & 46 & 1.00 \\
\hline 3 & 26 & 53.4 & 202 & 93.0 & 2.51 & 47 & 1.04 \\
\hline 4 & 26 & 52.2 & 199 & 76.8 & 2.15 & 41 & 1.20 \\
\hline 5 & 26 & 68.7 & 190 & 123.0 & 3.03 & 44 & 1.15 \\
\hline 6 & 24 & 59.6 & 178 & 72.0 & 2.69 & 45 & 1.14 \\
\hline
\end{tabular}

-Wt. = Weight in kilograms

-Max. HR= Maximum heart rate in beats per minute

¿V̀E= Maximal ventilation in liters per minute $\dot{v} \mathrm{O}_{2}=$ Maximal oxygen consumption in liters per minute $\ddot{\vee} 0 \mathrm{zml} .=$ Maximal oxygen consumption in milliliters per kilogram body weight per minute * $R=$ Respiratory quotient at maximal exercise 
Table 2

Experimental Test Schedule

Day

Group A

Day

Group B

$1 \grave{\mathrm{V}}=\mathrm{max}$. test administered 2

3

4 Subjects exercised at $75 \%$ $\dot{\mathrm{VO}}=\mathrm{max}$. for 1 hour and began carbohydrate loaded diet

5 Carbohydrate loaded diet

6 Carbohydrate loaded diet

7 Subjects exercised at $60 \%$ $\dot{\mathrm{V}} \mathrm{O}=\mathrm{max}$. for 1 hour

8

9

10

11

12 Subjects exercised at $75 \%$ voz max. for 1 hour and began carbohydrate depleted diet

13 Subjects exercised at $60 \%$ $\mathrm{VO}_{2} \max$. for 1 hour
40) $\mathrm{vO}_{2}$ max. test administered

41

42

43 Subjects exercised at 75 ن̀z max. for 1 hour and began carbohydrate depleted diet

44 Subjects exercised at $60 \%$ Ṽoz max. for 1 hour

45

46

47

48

49

50 Subjects exercised at $75 \% \mathrm{VO}_{2}$ max. for 1 hour and began carbohydrate loaded diet

51 Carbohydrate loaded diet

52 Carbohydrate loaded diet

53 Subjects exercised at $60 \% \mathrm{~V}_{2}$ max. for 1 hour 
placed on a carbohydrate depleted diet. The next day subjects exercised at 60 perent $\dot{V}_{2}$ max. for 1 hour. One month later $\dot{V}_{2}$ max. was determined for the three subjects in group B. Five days later subjects exercised at 70 to 75 percent $\dot{V}_{2}$ max. for 1 hour and were placed on the carbohydrate depleted diet. The next day they exercised at 60 percent $\mathrm{V}^{2} \mathrm{z}$ max. for 1 hour. One week later they exercised at 70 to 75 percent $\dot{V}_{2}$ max. for 1 hour and were placed on the carbohydrate loaded diet for 3 days. Subjects then returned to the 1 ab and exercised for 1 hour at 60 percent vo max. so that both groups exercised following a carbohydrate loaded and a carbohydrate depleted diet.

\section{Exercise Sessions}

\section{Maximum Oxyaen Consumption}

Maximum oxygen consumption was determined for all subjects on a Quinton Treadmill (model 18-60) using the Bruce protocol (See Table 3). Work bouts at each stage consisted of three minutes of exercise. The subjects exercised to voluntary exhaustion or when the oxygen uptake $\left(\mathrm{V}_{\mathrm{O}}\right)$, as analyzed by the computer interfaced to gas collection instruments, showed a progressive decline indicating that maximum oxygen uptake had been reached. During the exercise, pulmonary ventilation $(\dot{V} e), \quad \dot{V}_{2} 1 \mathrm{~min}^{-1}, \dot{V}_{2} \mathrm{ml} \mathrm{kg}^{-1} \mathrm{~min}^{-1}$, heart rate (HR), and respiratory quotient $(R Q)$ were monitored with an on-line metabolic monitoring system.

\section{Submaximal Exercise}

Prior to being placed on a specific diet, all subjects exercised for 1 hour at 70 to 75 percent $\dot{V} Q_{2} \max$. to deplete their muscle 
Table 3

Bruce Protocol a for Maximum $\mathrm{O}_{2}$ Consumption Tests on a Treadmill

\begin{tabular}{llll}
\hline Stage & Minutes & Speed & Grade \\
\hline 1 & 3 & $1.7 \mathrm{mph}$ & $10 \%$ \\
2 & 3 & $2.5 \mathrm{mph}$ & $12 \%$ \\
3 & 3 & $3.4 \mathrm{mph}$ & $14 \%$ \\
4 & 3 & $4.2 \mathrm{mph}$ & $16 \%$ \\
5 & 3 & $5.0 \mathrm{mph}$ & $18 \%$ \\
7 & 3 & $5.5 \mathrm{mph}$ & $20 \%$ \\
\hline
\end{tabular}

-Ellestad, Myruin H. Stress Testing Priciples and Practice.

Philadelphia: F. A. Davis Company, 1976. 
glycogen stores (Bergstrom et al., 1967). The v0z was monitored and treadmill speed was adjusted at 15 and 45 minutes of exercise to ensure subjects performed at appropriate oxygen consumption.

Each subject also completed 1 hour of exercise at 60 percent $\dot{v}_{0}$ max. after 3 days of carbohydrate loading and after 24 hours of carbohydrate depletion.

\section{Treatments}

A carbohydrate loaded diet was maintained for 3 days after the initial 1 hour exercise period at 70 to 75 percent ${ }^{*} \mathrm{O}_{2}$ max. for 1 hour. The diet consisted of 1500 to $2300 \mathrm{Kcals}$ a day. Subjects were instructed to eat only food appearing on the carbohydrate loaded diet list (Appendix B) and to record all food consumed.

A carbohydrate depleted diet was maintained for 1 day following exercise at 70 to 75 percent $\hat{V}_{2}$ max. for 1 hour. The diet consisted of 800 to $1200 \mathrm{Kcals}$ and 0 percent carbohydrates. The subjects received a carbohydrate depleted list (Appendix C) and were instructed to record all food eaten.

The subjects monitored their own diet on a list provided. One subject did not comply with the carbohydrate depleted diet.

\section{Measurements}

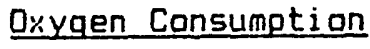

Oxygen consumption $\left(\hat{V}_{2}\right)$ was monitored with a computerized, on-line, open-circuit system. The subjects inspired room air and expired through a Daniel's valve, and expired air was collected and mixed in a plastic mixing chamber. The volume of gas was determined with a Bionix 400 pneumotachograph before it entered the mixing 
chamber. Expired gas was sampled from the mixing chamber at a rate of $500 \mathrm{cc} \bullet \mathrm{min}^{-1}$ and analyzed for percent oxygen with an Applied Electrochemistry S-3A oxygen analyzer and for percent carbon diaxide with a Beckman LB-2 carbon dioxide analyzer.

The instruments were directly interfaced through an Interactive Data System A/D converter to an Apple II computer. On-line metabolic calculations were rendered at 16 second intervals. Dxygen consumption was calculated using a standard formula (Astrand \& Fodahl, 1970) and displayed on an Apple Model II Monitor. Oxygen consumption was standardized to STPD. The gas analyzers were calibrated with a gas of known concentration which was verified by the Schol ander apparatus.

\section{Heart Fiate}

Heart rate (HR) was monitored with a Quinton 621-B Electrocardiogram monitoring system. Electrodes were set up with the negative electrode placed two inches below the union of the sterum and clavicle and the positive electrode on the fifth rib, below the pectoralis muscle. The third electrode was placed below the negative electrode and acted as a ground.

\section{Blood Analysis}

Blood samples were taken immediately before exercise, at 15 and 60 minutes of exercise, after 15 minutes of recovery, and at 60 minutes of recovery. Each sample consisted of ten cc's of blood drawn from the antecubital vein, using a vacutainer without anticoagulant. The blood was refrigerated until the final sample was drawn and immediately centrifuged. The serum was then analyzed with 
the Bio-Dynamic Unitest Systems for serum glucose and serum urea nitrogen.

Design

This study used a repeated measures design with each subject performing exercise following a carbohydrate loaded and a carbohydrate depleted diet. The order of the diet for each subject was randomly assigned.

\section{Statistical Analysis}

Serum urea nitrogen and glucose data were analyzed using t-tests to determine if: (a) any differences were found between the preexercise levels and measurements taken during exercise and recovery, and (b) there were any significant differences between the carbohydrate loaded and depleted diets. A Pearson Froduct Moment Correlation Coefficient was performed to determine the relationship between serum urea nitrogen and serum glucose. Hypotheses were tested at the .05 level of significance. 
CHAFTEF IV

Results and Discussion

\section{Results}

The raw data gathered during this study are presented in Appendices $D$ and $E$. Statistical analyses were performed using data from only five subjects because subject number six failed to maintain dietary restrictions.

Effects of Carbohydrate Loaded and Carbohydrate Depleted Diets on

Serum Glucose and Serum Urea Nitrogen

Statistical analyses presented in Table 4 showed no significant differences in serum glucose concentrations following the carbohydrate loaded and carbohydrate depleted diets. The effects of the two diets on serum urea nitrogen are presented in Table 5 . There were significant differences at all five sample times, with 15 minutes of exercise and 15 minutes of recovery being significant at the $\mathrm{e} \times .01$.

\section{Effects of Diet and Exercise of Serum Glucose}

The results of serum glucose tests are shown in Table 6 . The serum glucose after the carbohydrate loaded diet showed a statistically significant decrease only at 15 minutes of exercise. There were no statistically significant differences between preexercise levels and samples collected at 60 minutes of exercise, 15 minutes of recovery, or 60 minutes of recovery.

Following the carbohydrate depleted diet, there was a significant difference between preexercise serum glucose and serum 
Table 4

Effects of Carbohydrate Loaded and Carbohydrate Depleted

Diets on Serum Glucose for Five Subjects

Before, During, and After 1 Hour of Exercise at $60 \% \dot{v}_{2}$ max.

Mean- $\underline{\underline{s}}$

Freexercise

Carbohydrate loaded

101.2

17.17

1.41

Carbohydrate depleted

89.8

8.6

$15 \mathrm{~min}$. of exercise

Carbohydrate loaded

88.4

21.89

.14

Carbohydrate depleted

87.0

5.09

$60 \mathrm{~min}$. of exercise

Carbohydrate loaded

99.6

20.98

1.66

Carbohydrate depleted

81.8

6.30

$15 \mathrm{~min}$. of recovery

Carbohydrate loaded

103.8

26.72

Carbohydrate depleted

83.2

11.71

$60 \mathrm{~min}$. of recovery

Carbohydrate laaded

106.4

17.34

2.84

Carbohydrate depleted

84.2

6.72

$m \mathrm{mg} / 100 \mathrm{ml}$.

o $\underline{\text { SD }}=$ Standard deviation 


\section{Table 5}

Effects of Carbohydrate Loaded and Carbohydrate Depleted

Diets on Serum Urea Nitrogen for Five Subjects

Before, During, and After 1 Hour of Exercise at $60 \% \dot{v}_{2} \max$.

Freexercise

$\begin{array}{lccc}\text { Carbohydrate loaded } & 6.8 & 2.68 & -4.54 * * \\ \text { Carbohydrate depleted } & 16.8 & 6.35 & \end{array}$

$15 \mathrm{~min}$. of exercise

$\begin{array}{lccc}\text { Carbohydrate loaded } & 6.0 & 4.3 & -13.00 * * \\ \text { Carbohydrate depleted } & 19.0 & 5.29 & \end{array}$

$60 \mathrm{~min}$. of exercise

Carbohydrate loaded

$6.3 \quad 5.42 \quad-6.31 * *$

Carbohydrate depleted

$18.2 \quad 6.94$

15 min. of recovery
Carbohydrate loaded
5.6
6.58
$-11.21 * *$
Carbohydrate depleted
19.1
6.52

$60 \mathrm{~min}$. of recovery

Carbohydrate loaded

6.4

5.89

$-3.63 *$

Carbohydrate depleted

17.5

9.82

$m \mathrm{mg} / 100 \mathrm{ml}$.

' $\underline{\underline{S D}}$ = Standard deviation

$* \mathrm{~g}<.05, \underline{t}=2.77, \quad d f=4$

$* * \mathrm{e}<.01, t=4.60, d f=4$ 
Table 6

Statistical Analyses for Serum Glucose Concentrations

Before, During, and After 1 Hour of Exercise

at $60 \% \hat{\mathrm{V}}_{2}$ max. for Five Subjects

Sample time

Following Carbohydrate Loaded Diet

\begin{tabular}{|c|c|c|c|c|}
\hline Preexercise & 101.2 & 17.17 & & \\
\hline $15 \mathrm{~min}$. of exercise & 88.4 & 21.89 & $3.03 *$ & \\
\hline $60 \mathrm{~min}$. of exercise & 99.6 & 20.98 & .18 & \\
\hline $15 \mathrm{~min}$. of recovery & 103.8 & 26.72 & -.20 & -.78 \\
\hline $60 \mathrm{~min}$. of recovery & 106.4 & 17.34 & 1.30 & -.11 \\
\hline
\end{tabular}

Following Carbohydrate Depleted Diet

\begin{tabular}{|c|c|c|c|c|}
\hline Preexercise & 89.8 & 8.67 & & \\
\hline $15 \mathrm{~min}$. of exercise & 87.0 & 5.09 & 1.30 & \\
\hline $60 \mathrm{~min}$. of exercise & 81.8 & 6.30 & 1.73 & \\
\hline $15 \mathrm{~min}$. of recovery & 83.2 & 11.71 & 1.14 & -.50 \\
\hline $60 \mathrm{~min}$. of recovery & 84.2 & 6.72 & $3.43^{*}$ & -.68 \\
\hline
\end{tabular}

$=m g / 100 \mathrm{ml}$.

' $\underline{\underline{S D}}$ = Standard deviation

$c=$ Preexercise serum glucose compared to exercise and recovery serum glucose

$₫=$ Serum glucose at 60 minutes of exercise compared to recovery

$\mathrm{E}<.05, t=2.77, \mathrm{df}=4$ 
glucose only at 60 minutes of recovery. There were no significant differences during exercise or at 15 minutes of recovery. Effects of Diet and Exercise on Serum Urea Nitrogen

During exercise, no statistical significant differences were found between preexercise levels of serum urea nitrogen and samples following the carbohydrate loaded and depleted diets. The analyses of serum urea nitrogen data are presented in Table 7. There was a significant difference between 60 minutes of exercise and 15 minutes of recovery only after the carbohydrate depleted diet.

Rel ationship Getween Glucose and Serum Urea Nitrogen

The correlations between glucose and serum urea nitrogen following the carbohydrate loaded and depleted diets are presented in Table 8. There were no significant relationships between preexercise and samples taken during exercise and recovery, but there was a moderate relationship at 60 minutes of exercise following the carbohydrate loaded diet. Following the carbohydrate depleted diet, there were no significant relationships between preevercise and samples taken during exercise and recovery, but there was a weak. relationship at 15 minutes of exercise. 
Table 7

Statistical Analyses for Serum Urea Nitrogen Concentrations

Before, During, and After 1 Hour of Exercise

at $60 \% \dot{\mathrm{V}} 2 \mathrm{max}$. for Five Subjects

Sample time Mean

Differences Following Carbohydrate Loaded Diet

\begin{tabular}{|c|c|c|c|c|}
\hline Preexercise & 6.8 & 2.68 & & \\
\hline 15 min. of exercise & 6.0 & 4.30 & .44 & \\
\hline $60 \mathrm{~min}$. of exercise & 6.2 & 5.45 & .26 & \\
\hline $15 \mathrm{~min}$. of recovery & 5.6 & 6.58 & .48 & .50 \\
\hline $60 \mathrm{~min}$. of recovery & 6.4 & 5.89 & .17 & -.53 \\
\hline
\end{tabular}

Differences Following Carbohydrate Depleted Diet

Freexercise

$15 \mathrm{~min}$. of exercise

15 min. of recovery

$60 \mathrm{~min}$. of recovery
$60 \mathrm{~min}$. of exercise

16.4

6.50

19.0

5.29

18.2

19.0

17.4

$a=m g / 100 \mathrm{ml}$.

$\stackrel{\underline{S D}}{=}$ Standard deviation

$c=$ Freexercise serum urea nitrogen compared to exercise and recovery serum urea nitrogen

$d=S e r u m$ urea nitrogen at 60 minutes of exercise compared to recovery $* \mathrm{e}<.05, \underline{t}=2.77, \mathrm{df}=4$ 
Table 8

Relationship Between Serum Glucose and Serum Urea Nitrogen Following A Carbohydrate Loaded Diet and a Carbohydrate Depleted Diet

Relationship Following 3 days of Carbohydrate Loaded Diet

$\begin{array}{lll}\text { Freexercise } & -.0749 & .452 \\ 15 \mathrm{~min} . \text { of exercise } & -.3186 & .301 \\ 60 \mathrm{~min} . \text { of exercise } & -.7353 & .078 \\ 15 \mathrm{~min} . \text { of recovery } & -.4526 & .222 \\ 60 \mathrm{~min} . \text { of recovery } & -.5982 & .143\end{array}$

Relationship Following 24 Hours of a Carbohydrate Depleted Diet

Preexercise

$15 \mathrm{~min}$. of exercise

$60 \mathrm{~min}$. of exercise

$15 \mathrm{~min}$. of recovery

$60 \mathrm{~min}$. of recovery
.2000

.6764

.3398

.0209

.1495
.374

.105

.288

.487

.405

- Fearson Product Moment Correlation Coefficient

2-tail probability 


\section{Discussion}

In studying the sources of energy for muscular work, most physiologists have focused their investigations on carbohydrates and free fatty acids. The contribution of amino acid metabolism to energy production has been considered almost nonexistant. Recent literature indicates that protein may play a more important role in supplying fuel and providing tricarboxylic acid intermediates than previously believed.

\section{Serum Urea Nitrogen}

One of the research hypotheses for this study was that a significant increase in serum urea nitrogen would occur in response to exercise in a carbohydrate depleted state. Lemon and Mullins (1980) reported that during exercise at 70 to 75 percent $\dot{v}_{2}=\max$. following a carbohydrate depleted diet, serum urea nitrogen increased 7 and 16 percent at 15 and 60 minutes of exercise for male subjects. Following a carbohydrate loaded diet there were no significant differences during exercise. In another investigation, men exercising for 15 minutes on a 5 percent grade at 14 kilometers an hour showed a 25 percent increase in serum urea nitrogen (Rougier and Babin, 1975).

In the present study, subjects did not show a significant increase in serum urea nitrogen during exercise after the carbohydrate depleted or loaded diet. The exercise period at 60 percent $\dot{V}_{2}$ max. for 1 hour may not have been sufficient intensity or duration to demand protein utilization in women subjects and thereby cause an increase in serum urea nitrogen. Also, the exercise period 
at 70 to 75 percent $\dot{V}_{2}$ max. for 1 hour, used to deplete initial muscle glycogen stores may not have been long enough to deplete muscle glycogen stores in women. Hermansen et al., (1967) demonstrated that muscle glycogen concentrations could be significantly decreased by exercising at 75 percent $\mathrm{V}_{\mathbf{z}}$ max. to complete exhaustion. Bergstrom et al., (1967) reported that muscle glycogen could be significantly increased by providing subjects with a carbohydrate loaded diet for 3 days following an exercise period at 75 percent $\mathrm{VO}_{2}$ max. for approximately 2 hours. Also, subjects who were fed a protein diet following an exercise period at 75 percent VOO $=$ max. for approximately 2 hours showed only 50 percent of their initial muscle glycogen levels. The present study, and the study by Lemon and Mullins (1980), used only a 1 hour exercise period at 70 to 75 percent $\dot{V}_{2}$ max. to deplete subjects initial muscle glycogen levels prior to the assignment of a carbohydrate loaded or depleted diet.

Another factor which may have influenced the results of this study is the degree of training for each subject. Dohm, Hecker, Brown, Klain, Puente, Askew, and Beecher (1977) reported that amino acid catabolism was increased during exercise training with rats on a daily progressive exercise program for 6 weeks. Urea nitrogen excretion increased in trained rats compared to untrained rats. Also, muscle enzymes used in leucine oxidation increased as an adaptation to endurance training. Although each subject in the present study was physically active, none of them were involved in a training program. Perhaps the subjects in Lemon and Mullins' (1980) 
study were involved in a training program which increased their urea nitrogen excretion.

During recovery Lemon and Mullins (1980) found that serum urea nitrogen continued to increase at all sampling times, reaching an increase of 31 percent at 4 hours of recovery. Rougier and Babin (1975) reported a 48 percent increase after 1 hour of recovery. In their study, no attempt was made to alter initial muscle glycogen, and yet they still recorded significant increases in blood urea. The present investigation found a significant increase at 15 minutes of recovery following the carbohydrate depleted diet but no increase following the carbohyorate loaded diet. The serum urea nitrogen did not continue to increase and at 60 minutes of recovery there was no significant difference between 60 minutes of exercise and 60 minutes of recovery. One possible explanation for the lack of a significant increase at 1 hour of recovery may be related to the supply of available substrates. If the muscle glycogen stores were not sufficiently decreased during exercise then the need for the liver to produce glucose would be decreased.

\section{Serum Glucose}

Both the intensity and duration of the exercise affected the glucose concentrations in the present study and in a number of other studies. The glucose utilization by the muscles caused a significant decrease in serum glucose at 15 minutes of exercise after the carbohydrate loaded but not after the carbohydrate depleted diet in the present study. Subjects also showed a significant decrease at 60 minutes of recovery following the carbohydrate depleted diet compared 
to preexercise levels. Bergstrom et al., (1967) also found glucose concentrations decreased at 45 minutes of exercise at 75 percent VOa max. after a high carbohydrate diet. Hermansen et al., (1967) also reported a decrease at 20 minutes of exercise at 76 percent $\dot{\mathrm{VO}} \mathrm{z} \max$. and then the concentration remained relatively constant until exhaustion. At 30 percent $\mathrm{V}_{2}$ max., Ahlborg et al., (1974) found the glucose remained unchanged at 40 minutes of exercise, and then it gradually decreased 30 percent after 4 hours of exercise. Since subjects were able to maintain glucose homeostasis during exercise at 60 percent $\dot{V}_{0}$ max. after the carbohydrate depleted diet, they may have been relying on remaining muscle glycogen stores for energy.

Bergstrom et al., (1967) found that the blood glucose concentrations had decreased to extremely low levels at the end of 1 hour of exercise at 75 percent $\mathrm{VO}_{2}$ max. following a protein diet. Their subjects reported that they experienced headaches, dizininess, and general fatigue. Although the serum glucose levels at 60 minutes of recovery followng the carbohydrate depleted diet in the present study were within the normal range of $60 \mathrm{mg} / \mathrm{dl}$ to $110 \mathrm{mg} / \mathrm{dl}$, two subjects reported they felt light headed, fatigued, dizzy, nauseous, and one vomited. These side effects occurred within 2 and 5 hours of recovery. The other subjects had no side effects and were able to continue their normal activities. There were no side effects reported after the carbohydrate loaded diet. Serum glucose which was significantly lower after the carbohydrate depleted diet may have continued to decrease after the first hour of recovery and caused 
these side effects to appear later.

\section{Relationship between Serum Urea Nitrogen and Serum Gl ucose}

In viewing the proposed glucose alanine cycle, it seemed reasonable to investigate the relationship between glucose and serum urea nitrogen. Several investigations have examined the relationship between glucose and amino acid metabolism. Felig and Wahren (1971) reported a direct correlation between arterial alanine concentration and arterial pyruvate concentration during rest and exercise. Also a direct correlation between arterial alanine and arterial pyruvate was found at 5, 20, and 40 minutes of recovery (Wahren et al., 1973). In the present study, the data did not support the second hypothesis that there was a significant relationship between serum urea nitrogen and serum glucose. All the correlation coefficients following the carbohydrate loaded diet were negative and all the correlation coefficients following the carbohydrate depleted diet were positive. Although not significant, the negative correlations indicated that following a carbohydrate loaded diet serum urea nitrogen decreased as serum glucose increased. This relationship was the strongest at 1 hour of exercise with a -.73 correlation. The positive correlation following the carbohydrate depleted diet indicated that serum glucose and serum urea nitrogen increased or decreased at the same time. These correlations were very weak with the exception of .67 at 15 minutes of exercise.

A decrease in glucose concentration accompanied by an increase in serum urea nitrogen was expected after both diets, with a greater decrease in serum glucose and a greater increaase in serum urea 
nitrogen after the carbohydrate depleted diet. The negative correlation following the carbohydrate loaded diet seems to suggest that the high level of glucose provided sufficient fuel and therefore there was not an increase in serum urea nitrogen. The positive relationship following the carbohydrate depleted diet may suggest that the glucose al anine cycle was able to maintain glucose homeostasis by increased gluconeogenesis. This would account for the increase in glucose concentrations while there were also increases in serum urea nitrogen concentrations.

Compari sons Between the Carbohydrate Loaded and Depleted Di ets

When comparing the results following the carbohydrate loaded and depleted diets, the present study found a number of differences. A few have already been discussed such as the side effects reported only after the carbohydrate depleted diet and the non-significant positive and negative correlations between serum urea nitrogen and glucose following the carbohydrate depleted and loaded diets respectively. The serum urea nitrogen concentrations after the carbohydrate depleted diet, were significantly higher than the concentrations after the carbohydrate loaded diet including samples taken immediately before exercise. This is not consistant with Lemon and Mullins (1980) who reported there were no significant differences between carbohydrate loaded and depleted serum urea nitrogen samples taken before exercise. The increase in serun urea nitrogen may indicate that diet can influence the use of protein for fuel during rest and exercise.

During exercise, differences were noticed in the respiratory 
quotients (RQ) following the carbohydrate loaded and depleted diets. $R Q$ was recorded for subjects at 1 minute of exercise, 15 minutes of exercise and at 45 minutes of exercise. RQ's ranged from .69 to .80 following the carbohydrate depleted diet with a mean of .73 . Following the carbohydrate loaded diet, RQ's ranged from .78 to .96 with a mean of .84 . These values seem to be consistant with Bergstrom et al., (1967) who reported the RQ for male subjects exercising at 75 percent $\dot{V}_{\mathbf{z}}$ max. following a carbohydrate diet was .94 at 30 minutes of exercise. The RQ was .81 following a protein diet. There was a significant difference between the protein and carbohydrate diets RQ's in Bergstrom et al., (1967) study. The differences in RQ's after the carbohydrate loaded and depleted diets seems to demonstrate that diet can influence the contribution of carbohydrates, fats, and possibly protein during exercise. 
CHAFTER $V$

Summary, Conclusions, and Fiecommendations

\section{Summary}

The purpose of this study was to determine the effects of initial muscle glycogen on serum urea nitrogen during 1 hour of exercise at so percent $\dot{\mathrm{V}}_{\mathbf{z}}$ max. in women. Subjects were six female subjects between the ages of 23 and 30 years. Maximum oxygen consumption was determined using Bruce protocal on a treadmill. Each subiect $r$ an on a treadmill for one hour at 70 to 75 percent of their $\mathrm{VO} z$ max. before being randomly placed on a 3 day carbohydrate loaded or 24 hour carbohydrate depleted diet. After following the appropriate diet, the subjects returned to the 1 ab and $r$ an for one hour at 60 percent $\mathrm{VO}_{2} \max$. Blood samples were drawn before exercise at 15 minutes of exercise, 60 minutes of exercise, 15 minutes of recovery and so minutes of recovery. Samples were tested for serum urea nitrogen and glucose concentrations. Subjects then switched diets and followed appropriate exercise schedules.

t-tests were used to determine if there were differences between preexercise, exercise, and recovery, and between carbohydrate loaded and carbohydrate depleted conditions. A Fearson Product Moment Correlation Coefficient was used to determine if there was a significant relationship between serum olucose and serum urea nitrogen. Only data for five subjects were analyzed because one sub ject failed to follow dietary restrictions.

During exercise there were no significant changes in serum urea 
nitrogen. There was a significant increase in serum urea nitrogen at 15 minutes of recovery following the carbohydrate depleted diet $(p<.05)$

At 15 minutes of exercise there was a significant decrease in glucose following the carbohydrate loaded diet. There was also a significant decrease in glucose at 60 minutes of recovery following the carbohydrate depleted diet.

The serum urea nitrogen concentrations following the carbohydrate depleted diet were significantly higher than the concentrations following the carbohydrate loaded diet at all sampling times.

There appears to be low to moderate relationships between serum urea nitrogen and serum glucose following both diets with the relationship at 1 hour of exercise following the carbohydrate loaded diet being the strongest.

\section{Conclusions}

Based on the results of this study, the following conclusions were drawn:

(1) Serum urea nitrogen levels can be significantly altered by administration of a carbohydrate loaded or depleted diet. After following a carbohydrate depleted diet, there is a significant increase in serum urea nitrogen which seems to indicate that under certain conditions such as low muscle glycogen levels, there is an increase in the contribution of protein as an energy source

(2) Although the serum urea nitrogen levels following the carbohydrate depleted diet were significantly higher than after the 
carbohydrate loaded diet, they did not significantly increase during exercise at 60 percent $\dot{V}_{2}$ max. for 1 hour. This suggests that the exercise did not demand further orotein utilization and that fats and carbohydrates provided the major source of energy along with the already increased contribution from protein

(3) During 1 hour of submaximal exercise following the carbohydrate depleted diet there were low to moderate positive relationships between serum urea nitrogen and serum glucose, which suggests that in addition to their role as fuel, amino acids may be involved in maintaining glucose homeostasis via the branched chain amino acid-alanine cycle.

Recommendations

The following recommendations are suggested for further research:

(1) the lean body weight should be measured to help explain differences between subjects or differences between men and women, (2) the diet list should specify the exact food to be eaten and the number of calories for each subject,

(3) subjects should maintain the carbohydrate depleted diet the same length of time they maintained the carbohydrate loaded diet, 3 days, (4) the study should cantinue to monitor subjects for 4 hours after exercise to help determine what caused the side effects, (5) a longer exercise period should be used to deplete subjects initial muscle glycogen stores to insure low muscle glycogen stores prior to diet assignments. 


\section{REFERENCES}

Astrand, P. \& Rodahl, K. Textbogk of Work Physiology. New York: McGraw-Hi11, 1970.

Astrand, P. \& Rodahl, K. Textbook of Work Physiology. New York: MeGraw-Hill, 1977.

Ahlborg, G., Felig, P., Hagenfelt, L., Hendler, R., \& Wahren, J.

Substrate turnover during prolonged exercise in man. Journal

of Clinical Investiqation, 1974, 53, 1080-1090.

Bergstrom, J., Hermansen, L., Hultman, E., \& Saltin, B. Diet, muscle

glycogen and physical performance. Acta Physiologica

Scandinavica, 1967, 21, 140-150.

Brodan, V., Kuhn, E., Fechar, J., \& Tomkova, D. Changes of free amino acids in plasma of healthy subjects induced by physical

exercise. European Journal of Applied Physiology, 1976, 36, $611-619$.

Chang, T., \& Goldberg, A. The origin of alanine produced in skeletal muscle. The Journal of Biological Chemistry, 1978, 253, $3677-3684$.

Consol azio, F., Johnson, H., Nelson, R., Dramise, J., \& Skala, J. Frotein metabolism during intensive physical training in the young adult. American Journal of Clinical Nutrition, 1975, 28, $29-35$.

Dohm, G., Hecker, A., Brown, W., Klain, G., Pliente, F., Askew, E., \& Beecher, G. Adaptation of protein metabolism to endurance training. Biochemistry Journal, 1977, 164, 705-708.

Ellestad, Myruin H. Stress Testing Principles and Practice. 
Philadelphia: F. A. Davis Company, 1976.

Felig, P., Owen, O., Wahren, J., \& Cahill, G. Amino acid metabolism during prolonged starvation. Journal of Clinical Investigation, $1969,48,584-594$.

Felig, F., Pozefsky, T., Marliss, E., \& Cahill, G. Alanine: key role in gluconeogenesis. Science, 1970, 167, 1003-1004.

Felig, F., \& Wahren, J. Amino acid metabolism in exercising man. Journal of Clinical Investiqation, 1971, 50, 2703-2714. (a)

Felig, P., \& Wahren, J. Influence of endogenous insulin secretion on splanchnic glucose and amino acid metabolism in man. Journal of Clinical Investiqation, 1971, 50, 1702-1711. (b)

Gaesser, G., \& Brooks, G. Glycogen repletion following continuous and intermittent exercise to exhaustion. Journal of Applied Physiology: Respiration, Environment, \& Exercise Physiology, $1980,40(4), 722-728$.

Garber, A., Karl, I., \& Kipnis, D. Alanine and glutamine synthesis and release from skeletal muscle. The Journal of Biological Chemistry, 1976, 251, 836-843.

Goldberg, A., \& Chang, T. Regulation and significance of amino acid metabolism in skeletal muscle. Federation Proceedings, 1978, 37. 2301-2307.

Goldberg, A., \& Odessey, R. Oxidation of amino acids by diaphragms from fed and fasted rats. American Journal of Physiology, 1972, $\underline{223}(6), 1384-1391$.

Goldstein, L., \& Newsholme, E. The formation of alanine from amino acids in diaphragm muscle of the rat. Biochemical Journal, 
$1976, \underline{154}, 553-558$.

Gontzoa, J., Sutzescu, R., \& Dumitrache, S. The influence of muscular activity on nitrogen balance and the need of man for protein. Nutrition Reports International, 1974, 10 (1), 35-43. Hermansen, L., Hultman, E., \& Saltin, B. Muscle glycogen during prolonged severe exercise. Acta Physiologica Scandinavica, 1967, 71, 129-139.

Lemon, F., \& Mullins, J. Effect of initial muscle glycogen levels on protein catabolism during exercise. Journal of Applied Physiology: Respiration, Environment, \& Exercise Physiology, $1980, \underline{48}(4), 624-629$.

Lowenstein, J. M. Ammonia production in muscle and other tissues: The purine nucleotide cycle. Physiological Reviews, 1972, $52(2), 382-414$

MacDougall, J., Ward, G., Sale, D., \& Sutton, J. Muscle glycogen repletion after high intensity intermittent exercise. Journal of Applied Physiology: Respiration, Environment, \& Exercise Physiology, 1977, $42(2), 129-132$.

Mallette, L., Exton, J., \& Park, C. Control of gluconeogenesis from amino acids in the perfused rat liver. Journal of Biological Chemistry, 1969, 244 (20), 5713-5723.

Mole, P., \& Johnson R. Disclosure by dietary modification of an exercise-induced protein catabolism in man. Journal of Applied Physiology, 1971, 31 (2), 185-190.

Odessey, F., Khairallah, E., \& Goldberg, A. Origin and possible significance of al anine produced by skeletal muscle. Journal 
of Biological Chemistry, 1974, 249 (23), 7623-7629.

Rougier, G., \& Babin, J. Blood and urine study of heavy muscular work on ureic and uric metabolism in man. Journal of Sports

Medicine, 1975, 15, 212-222.

Ruderman, N., \& Berger, M. The formation of glutamine and alanine in skeletal muscle. Journal of Biological Chemistry, 1974, $\underline{249}(17), 5500-5506$.

Schwartz, A., Lawrence, R., \& Roberts, K. Elevation of peripheral blood ammonia following muscular work. Proceedings of the Society for Experimental Bioloay and Medicine, 1958, 98, $548-550$.

Wahren J., Felig, P., Hendler, R., \& Ahlborg, G. Glucose and amino acid metabolism during recovery after exercise. Journal of Applied Physiol ooy, 1973, 34, 838-845. 
Appendix A

\section{Informed Consent Form}

You are invited to participate in a study which will provide information on protein catabolism for women during exercise after a carbohydrate loaded diet and a carbohydrate depleted diet. All subjects will exercise a total of five times, once after a carbohydrate loaded diet and once after a carbohydrate depleted diet.

If you decide to participate, you will first be asked to run and jog on a treadmill to determine your maximum oxygen consumption (ن⿺辶 ${ }^{\prime}$ ax.). This consists of running and jogging at increasing intensities until you reach a maximum level of oxygen consumption. You will be monitored by an electrocardiogram to determine your heart rate and any abnormal responses. This should take approximately a half an hour. This information will be used in following exercise periods.

Four days later you will be asked to exercise at $75 \%$ of your $\dot{\mathrm{V}} \mathrm{z}$ max. for 1 hour. Then you will be randomly assigned to a carbohydrate loaded diet (a diet high in carbohydrates) or a carbohydrate depleted diet (a diet with $0 \%$ carbohydrates). You will be responsible for maintaining and following guidelines given to you for that diet. The high carbohydrate diet will be maintained for 3 days and followed by an hour of exercise at $60 \% \dot{v}_{2}=\max$. The carbohydrate depleted diet will be maintained for one night and followed by an hour of exercise at $60 \% \dot{V}_{2}=\max$. During the exercise and during 1 hour of recovery a total of five blood samples will be drawn. The samples will be used to measure blood glucose and serum 
urea nitrogen.

One week later you will exercise at $75 \% \dot{v}_{z} \max$. , switch diets and follow the appropriate exercise schedule. The total amount of lab time at De Anza College Physiology Laboratory will be 7 1/2 hours over a 21 day period.

The exercise in this study may be accompanied by some physical discomfort, such as increased heart rate, sweating, sore muscles, and increased body temperature. There is a risk of certain complications occuring such as fainting, abnormal blood pressure, and heart beat disorders. If any abnormality is observed by the investigator or reported by you, the test will be discontinued.

If you have any questions regarding procedures please ask for an explanation. Any data collected in connection with this study will remain confidential.

Your decision whether or not to participate will not prejudice your future at Palmer College of Chiropractic-West or De Anza College. You are free to withdraw your consent and discontinue participation at any time.

YOUR SIGNATURE INDICATES THAT YOU HAVE READ AND UNDERSTAND THE ABOVE INFORMATION, ARE TO THE BEST OF YOUF KNOWLEDGE IN GOOD HEALTH, THAT YOU HAVE DISCUSSED THIS STUDY WITH THE INVESTIGATOR AND THAT YOU HAVE DECIDED TO FARTICIPATE BASED ON THE INFORMATION ABOVE.

(A copy of this form available to you upon request).

Signature of Volunteer Date

Signature of Investigator Date

Signature of Witness Date 
Appendix B

Carbohydrate Loaded Diet Lista

Food

Amount of Serving

Approximate No. of Kcals

Breads and Cereals

\begin{tabular}{|c|c|c|}
\hline cornflakes & 1 cup & 96 \\
\hline cracked wht. bread & 1 slice & 60 \\
\hline macaroni & 1 cup & 190 \\
\hline noodles (egg) & 1 cup & 200 \\
\hline oatmeal, cooked & 1 cup & 130 \\
\hline pancakes & 1, 4" diam. & 60 \\
\hline pizza & $1 / 8$ of small & 130 \\
\hline rice (enriched) & 1 cup & 225 \\
\hline rolls, plain & 1 & 120 \\
\hline rolls, sweet & 1 & 178 \\
\hline spaghetti, cooked & 1 cup & 220 \\
\hline waffles & 1, $4 \times 6$ & 210 \\
\hline white bread & 1 slice & 70 \\
\hline \multicolumn{3}{|l|}{ Fruits and Juices } \\
\hline apple & 1 med. & 87 \\
\hline applesauce & $1 / 2$ cup & 100 \\
\hline apricot & $1 / 2$ cup canned & 110 \\
\hline bananas & 1 med. & 100 \\
\hline grapefruit & 1 cup & 95 \\
\hline
\end{tabular}

-Agricultural Research Service. Nutritive value of foods. U.S.

Department of Agriculture, Home and Garden Bulletin. (Rev. ed.), 1971, No. 72. 
Food

grapefruit juice

or anges

orange juice

peaches, canned

pineapple

raisins, dry

strawberries (frozen)

tomato juice

Amount of Serving

1 cup

1 med.

1 cup

$1 / 2$ cup

$1 / 2$ cup

1 cup

302 .

1 cup

Veqetables

beets

$1 / 2$ cup

corn

$1 / 2$ cup

peas

$1 / 2$ cup

1

potatoes, baked

chips

10 med.

10 pieces

1 med.

$1 / 2$ cup

1 med.

tomatoes

french-fried

mashed

squash

Sugar and Sweets

candy, mild choc.

cake

crackers

cupcake

doughnut

jellies
$10 z$.

1, 2" piece

110

2

34

1, $2-3 / 4^{\prime \prime}$

161

1

136

1 tbsp.

55
45

30

85

Approximate No. of Kcals

130

65

120

100

95

480

82

60

90

115

155

125

65

30 
Food

jello, plain

marshmellos

pie, apple

pie, pumpkin

sugar, white or brown

\section{Bever ages}

beer

non-fat milk

soft drinks
Amount of Serving

2 cups

3-4

$1 / 6$ med. pie

$1 / 6$ med. pie

1 tsp.

15

8 ดz.

114

8 a..

87

802.

106

\section{Restrictions}

No food appearing on carbohydrate depleted list (Apperidix C) 
Appendix C

Carbohydrate Depleted Diet List *

Food

Amount of Serving

Approximate No. of Kcals

Fats, \& 0 ils

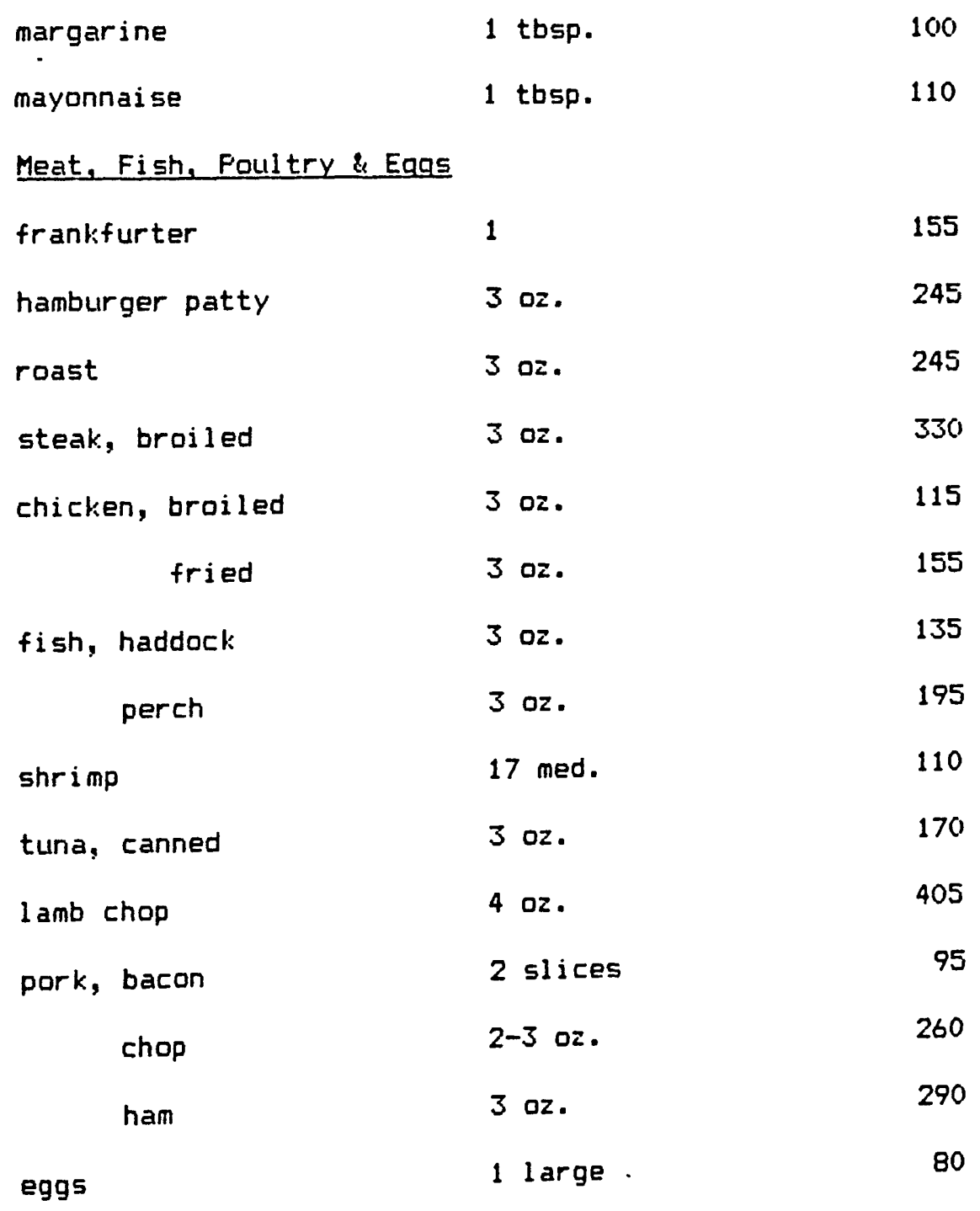

-Agricultural Research Service. Nutritive value of foods. U.S. Department of Agriculture, Home and Garden Bulletin. (Rev. ed.), 1971, No. $\underline{72}$. 
Beverages

coffee, tea, \& water

Restrictions

No food appearing on the carbohydrate loaded list (Appendix B). 
Appendix D

Serum Glucose Concentrations Before, During, and After 1 Hour of Exercise at $60 \% \mathrm{VO}_{2}$ max.

Exercise After 3 Days of Carbohydrate Loaded Diet

\begin{tabular}{lcccccc} 
Subiect & 1 & 2 & 3 & 4 & 5 & 6 \\
Sampling time & \multicolumn{1}{c}{ Serum } & Glucose & Concentrations & & \\
\hline Preexercise & 75 & 103 & 98 & 122 & 108 & 101 \\
15 minutes of exercise & 58 & 76 & 91 & 112 & 105 & 105 \\
60 minutes of exercise & 86 & 84 & 91 & 102 & 135 & 102 \\
15 minutes of recovery & 96 & 96 & 86 & 90 & 151 & 96 \\
60 minutes of recovery & 102 & 88 & 94 & 130 & 118 & 104
\end{tabular}

Exercise After 24 Hour Carbohydrate Depleted Diet

\begin{tabular}{lcccccc} 
Subiect & 1 & 2 & 3 & 4 & 5 & 6 \\
Sampling time & \multicolumn{1}{c}{ Serum } & Glucose Concentrations & \\
\hline Freexercise & 91 & 92 & 90 & 100 & 76 & 88 \\
15 minutes of exercise & 85 & 92 & 86 & 92 & 80 & 86 \\
60 minutes of exercise & 85 & 92 & 75 & 79 & 80 & 77 \\
15 minutes of recovery & 88 & 98 & 66 & 84 & 80 & 74 \\
60 minutes of recovery & 88 & 86 & 80 & 92 & 75 & 80 \\
\hline
\end{tabular}

$-m g / 100 \mathrm{ml}$. 
Appendix E

Serum Urea Nitrogen Concentrations Before, During, and After 1 Hour of Exercise at $60 \%$ voz max.

Exercise After 3 Days of Carbohydrate Loaded Diet

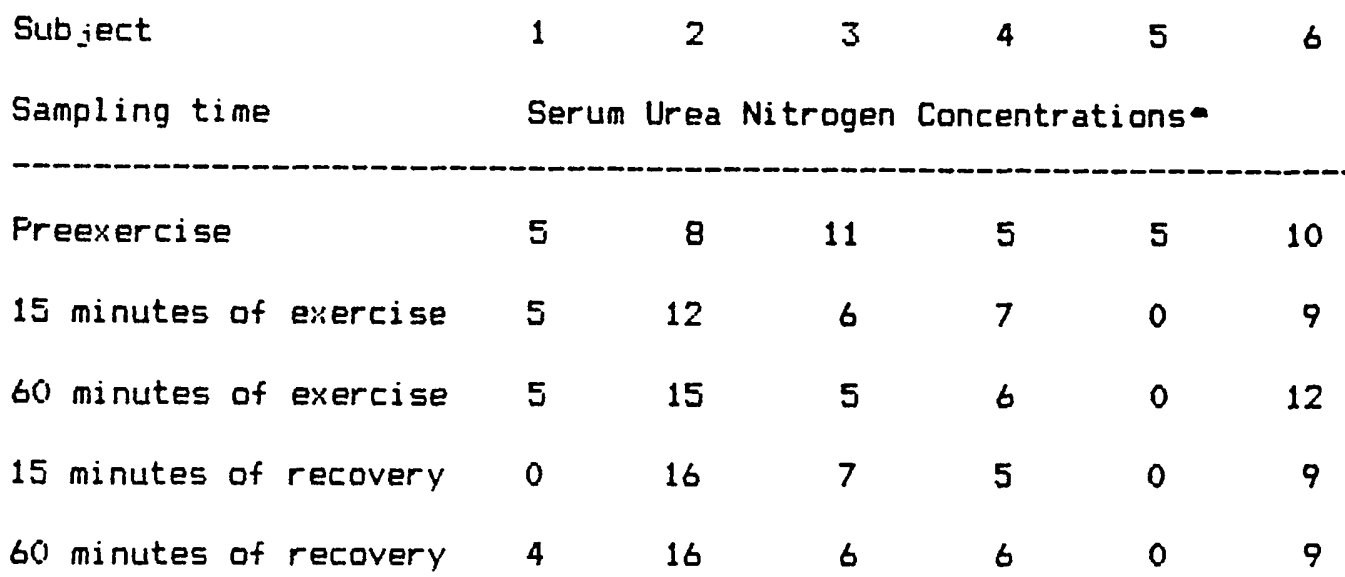

Exercise After 24 Hour Carbohydrate Depleted Diet

$\begin{array}{llllll}\text { Subject } & 1 & 2 & 3 & 4 & 5 \\ \text { Sampling time } & & \text { Serum Urea } & \text { Nitrogen } & \text { Concentrations }\end{array}$

$\begin{array}{lllllll}\text { Preevercise } & 14 & 26 & 20 & 11 & 11 & 15 \\ 15 \text { minutes of exercise } & 18 & 26 & 22 & 17 & 12 & 13 \\ 60 \text { minutes of exercise } & 12 & 27 & 24 & 16 & 12 & 14 \\ 15 \text { minutes of recovery } & 13 & 27 & 25 & 17 & 13 & 14 \\ 60 \text { minutes of recovery } & 18 & 27 & 27 & 10 & 5 & 14\end{array}$

$m g / 100 \mathrm{ml}$. 